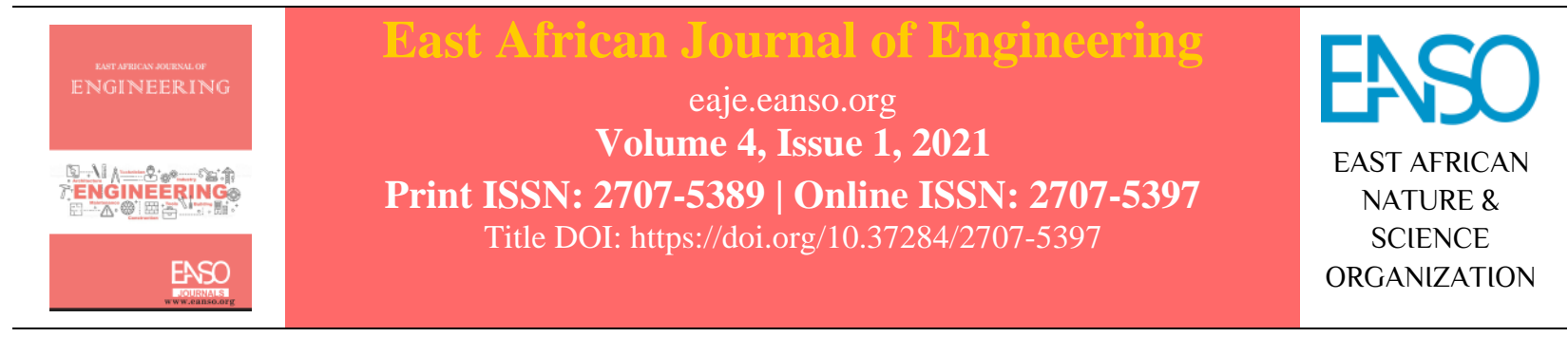

Original Article

\title{
Assessing Strength of Plastic Paving Blocks for Construction of Non- Motorised Transport Facilities.
}

\author{
Abigail Muigai ${ }^{1 *}$, Prof. Sixtus Mwea, $P h D^{2} \&$ Dr. Simpson Osano, $P h D^{2}$ \\ ${ }^{1}$ Transportation Engineer, Nairobi Metropolitan Area Transport Authority, P. O. 1790-00502 Karen, Kenya. \\ ${ }^{2}$ University of Nairobi, P. O. Box 30197 - 00200 Nairobi, Kenya. \\ * Author for Correspondence Email: abigailmuigai@gmail.com.
}

Article DOI: https://doi.org/10.37284/eaje.4.1.483

Publication Date: ABSTRACT

25 November 2021 Walking remains the oldest and most common mode of transport making up a portion if not most or all our daily commute. However, infrastructure Keywords: developments in our urban areas have a bias towards motorised transport leading to pedestrians and cyclists being the most affected in road incidents. Increasing non-motorised transport facilities in our urban centres would increase levels of walkability, reduce the number of crashes involving non-motorised transport users, reduce traffic congestion, noise and air pollution making them sustainable and more liveable. Three hundred million tonnes of plastic waste are produced annually in the world with Kenya contributing 407,506 tonnes. The waste produced shall continue to increase with increasing population, urbanisation and development. The non-biodegradability of plastic makes proper disposal of plastic waste a menace and due to widespread littering, plastic waste has become a common sight in our urban and rural areas. The conventional materials used for the construction of walkways and cycle lanes, asphalt and concrete are most ideal for the motorised transport pavements. Plastic paving blocks can be affordable, readily available and environmentally friendly making a suitable alternate construction material if adopted. This study assessed the strength of plastic paving blocks for use in the construction of walkways and cycle lanes; by undertaking a tensile strength test according to SANS 1058:2021 on samples provided by Corec Kenya. The samples satisfied all of the strength specifications and from this it can be recommended that the plastic paving blocks can be used on low traffic pavements such as walkways and cycle lanes.

\section{APA CITATION}

Muigai, A., Mwea, S., \& Osano, S. (2021). Assessing Strength of Plastic Paving Blocks for Construction of Non-Motorised Transport Facilities East African Journal of Engineering, 4(1), 33-38. https://doi.org/10.37284/eaje.4.1.483 


\section{CHICAGO CITATION}

Muigai, Abigail, Sixtus Mwea, \& Simpson Osano. 2021. "Assessing Strength of Plastic Paving Blocks for Construction of NonMotorised Transport Facilities". East African Journal of Engineering 4 (1), 33-38. https://doi.org/10.37284/eaje.4.1.483.

\section{HARVARD CITATION}

Muigai, A., Mwea, S., \& Osano, S. (2021) "Assessing Strength of Plastic Paving Blocks for Construction of Non-Motorised Transport Facilities”, East African Journal of Engineering, 4(1), pp. 33-38. doi: 10.37284/eaje.4.1.483.

\section{IEEE CITATION}

A., Muigai., S. Mwea., \& Osano, S. "Assessing Strength of Plastic Paving Blocks for Construction of Non-Motorised Transport Facilities," EAJE, vol. 4, no. 1, pp. 33-38, Nov. 2021.

\section{MLA CITATION}

Muigai, Abigail, Sixtus Mwea, \& Simpson Osano. "Assessing Strength of Plastic Paving Blocks for Construction of NonMotorised Transport Facilities." East African Journal of Engineering, Vol. 4, no. 1, Nov. 2021, pp. 33-38, doi:10.37284/eaje.4.1.483.

\section{INTRODUCTION}

\section{Background}

Over time road infrastructure developments have been focused on providing for Motorized Transport (MT) this is despite walking being the most dominant mode of transport leading to neglect of the majority in the modal split. Non-motorised transport users are forced to compete for space with motorised transport on the provided infrastructure leading to numerous roads incidents involving pedestrians and cyclists. The National Transport and Safety Authority reported that $65 \%$ of road fatalities involved pedestrians in 2017.

Pedestrians and cyclists are categorised as vulnerable road users, this is because of the lack of proper NMT infrastructures such as walkways and cycle lanes. A paradigm shift is necessitated to improve conditions for the Non-Motorised Transport users to reduce the number of crashes involving pedestrians and cyclists as well as stimulate an increase in levels of walkability in our cities and towns through the provision of proper Non-Motorised Transport infrastructure (walkways and cycle lanes).

The use of fossil fuels has increased levels of atmospheric carbon dioxide making climate change and global warming major emerging issues in today's world. The transportation sector is the second largest contributor to emissions contributing
$27 \%$ of greenhouse gas (GHG) emissions in the world; land transport being the main contributor to the GHG as a result of the combustion of the petroleum-based products used for propulsion. Emissions from the sector can be significantly reduced by encouraging the use of NMT.

The world is today producing 300 million tonnes of plastic waste with Kenya contributing 407,506 tonnes per year, with increasing population, urbanisation and development, the annual plastic waste produced is bound to increase. Plastics can remain on earth for 4,500 years without degeneration, this non-biodegradability property has made proper disposal of plastic waste a menace endangering the environment and all life forms. Despite the negative effects of plastic highlighted, a complete ban on the use of plastic is not feasible as every industrial sector; automobile, agriculture, packaging and building construction uses plastic because of its versatility and cheap large-scale production; therefore, avenues of reuse and recycling of plastic should be explored to reduce their impact on the environment.

Small enterprise companies have come up with plastic waste recycling into building materials such as roofing tiles, fencing poles, and paving blocks. One of the companies founded in 2015, Continental Renewable Energy Co. Ltd reports that it has so far ensured that 700 tons of plastic waste is recycled 
and, in the process creating hundreds of employment opportunities.

\section{Problem Statement}

One of the biggest environmental concerns in the world today is plastic waste due to the influx of plastic use in our society. The damage from plastic waste is long-lasting causing land, air and water pollution. There is inadequate NMT infrastructure within our cities and towns to cater for the demand and volumes experienced. The overall objective of this study was to analyse the strength of plastic paving blocks obtained from Continental Renewable Energy Company Limited - Corec Kenya for use in the construction of non-motorised transport facilities by establishing the tensile strength of the plastic paving blocks through laboratory tests.

\section{LITERATURE REVIEW}

The rise of global warming and climate change makes the use of plastic as an alternative material for pavement construction timely. Plastics are categorised broadly into thermoplastics and thermosets. The plastic waste generated constitutes
$80 \%$ thermoplastic and $20 \%$ thermosets (UNEP, 2009).

Thermoplastics are defined as plastic polymers that can be moulded into desired shapes under heat and pressure and become hard upon cooling. They can be subjected to heating and cooling several times without altering their chemical and mechanical properties. Thermosets contain polymers that crosslink and form an irreversible chemical bond during the curing process (IRC: SP:98-2013). Once formed they cannot be softened or remoulded by heat application. Table 1 shows the examples of the two types of plastics explained above.

The unique characteristic of the thermoplastics highlighted above makes them highly recyclable. They soften at temperatures between $130^{\circ}-140^{\circ} \mathrm{c}$ and gas evolution occur at temperatures beyond $180^{\circ} \mathrm{c}$. The guidelines for the use of plastic waste in hot bituminous mix stipulates that only plastics that conform to Polyurethane, PET, LDPE and HDPE shall be used for pavement construction. PVC should not be used under any circumstance as they release harmful and lethal dioxins when heated. Plastics black in colour as a result of repeated recycling should not be used (IRC: SP:98-2013).

Table 1: Types of Plastics (Thermoplastics and Thermosets)

\begin{tabular}{ll}
\hline Thermoplastic & Thermosetting \\
\hline Polystyrene (PS) & Alkyd \\
Polypropylene (PP) & Melamine \\
Poly Vinyl Chloride (PVC) & Bakelite \\
Polyethylene Teryphthalate (PET) & Urea - Formaldehyde \\
Poly Vinyl Acetate (PVA) & Epoxy \\
High Density Polyethylene (HDPE) & Polyester \\
Low Density Polyethylene (LDPE) & \\
\hline
\end{tabular}

Manufacturing the plastic paving blocks involves the collection of the plastic waste from various locations, sorting, cleaning and shredding into manageable sizes. The shredded plastic is heated to a temperature of $140^{\circ}-170^{\circ} \mathrm{c}$ and mixed with fine aggregate (sand). To avoid gas evolution, temperatures should not exceed $180^{\circ} \mathrm{c}$. The mixture is weighed, moulded, and cooled with water to produce the plastic paving block shown in Plate 1. 


\section{Plate 1: Plastic paving Block}

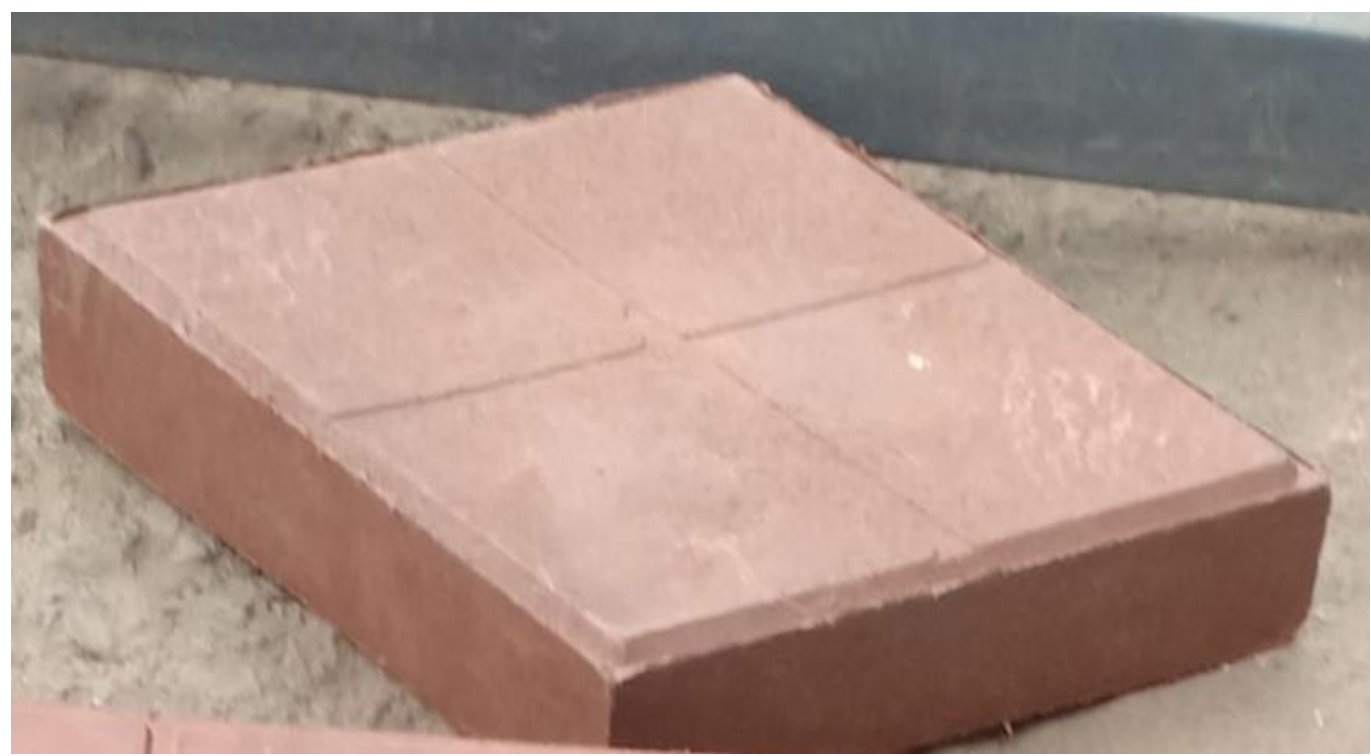

\section{MATERIALS AND METHODS}

\section{Measurement of Strength}

A load was applied smoothly and progressively on the plastic paving block increasing stress at a rate of
$(0.05 \pm 0.01) \mathrm{MPa} / \mathrm{s}$ and the failure load, $\mathrm{P}$ recorded. For preparation, five blocks were immersed in water for $24 \pm 3$ hours, wiped and immediately placed in the testing machine with the packaging pieces on the upper and bed face in contact with the bearers as shown in Plate 2.

\section{Plate 2: The prepared samples are placed in the strength testing machine}

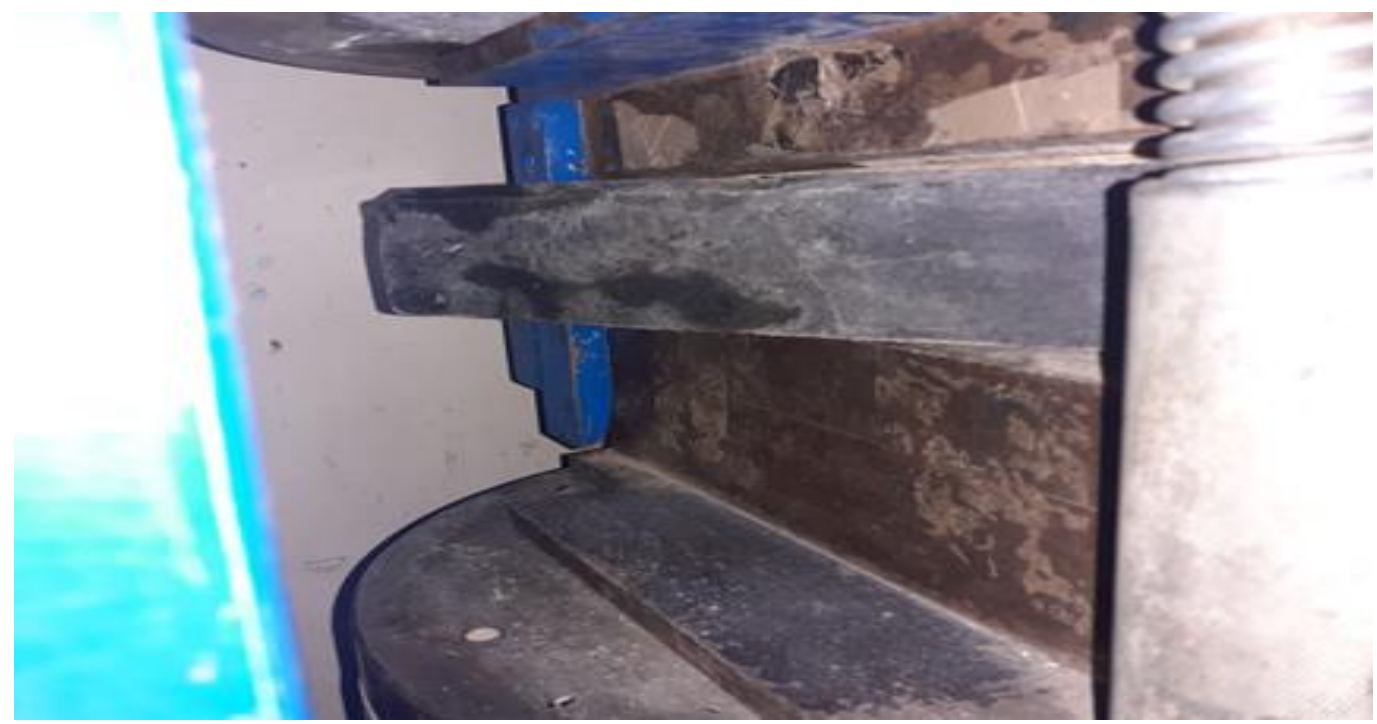

The area of failure, $\mathrm{S}\left(\mathrm{mm}^{2}\right)$ was then obtained by the failure length, $l$ one at the top; the other at the multiplying the mean of the two measurements of bottom of the block and the thickness of the block, $t$

36 This work is licensed under a Creative Commons Attribution 4.0 International License. 
at the failure plane and is the mean of three measurements; one at the middle and one at either end. Measurement of the failure length and thickness was done as shown in Plate 3 (a-b) to obtain the area of failure recorded in Table 2. Therefore, $\mathrm{S}=l \times \mathrm{t}$

Plate 3: The failure plane of the specimen is measured

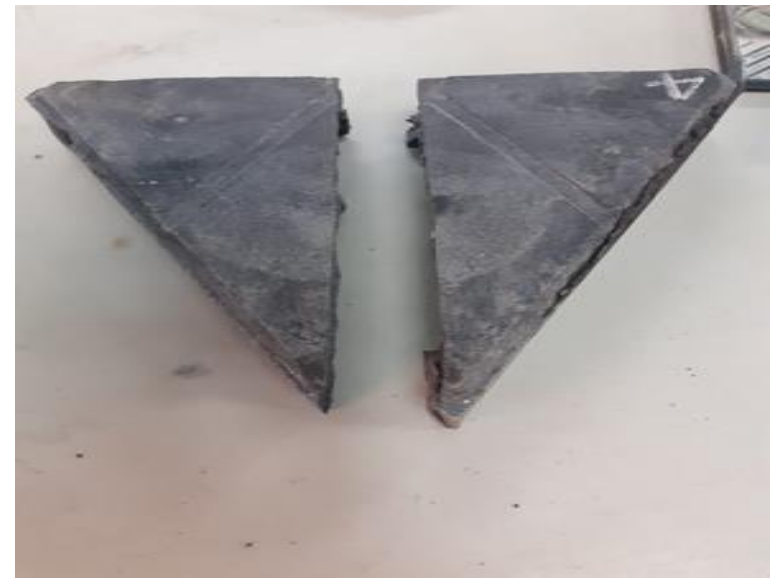

a

The obtained failure area and recorded failure load are used to calculate the strength $T$ in megapascal of the block using the following formula:

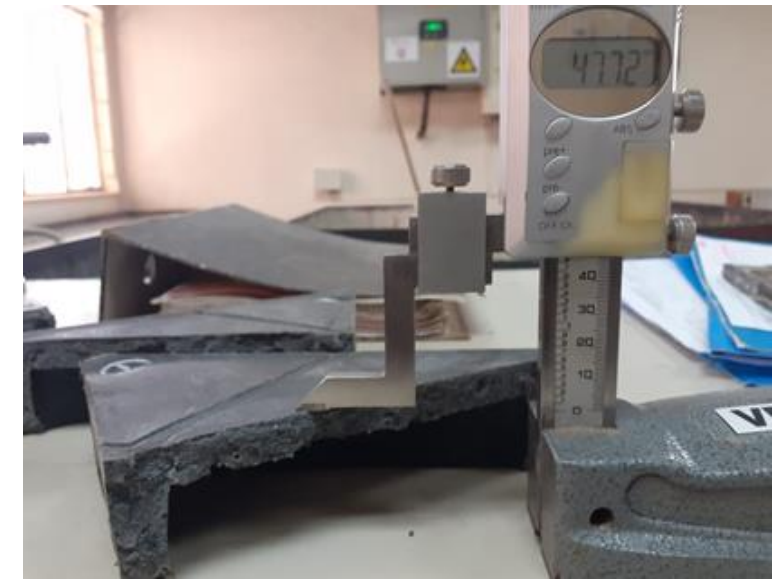

b

Table of the correction factor, $\mathrm{k}$ if $\mathrm{t} \leq 140$.

Table 2: Value of $\mathrm{K}$ for $\mathrm{t} \leq \mathbf{1 4 0}$

\begin{tabular}{|l|l|l|l|l|l|l|l|l|l|l|l|}
\hline $\mathrm{t}(\mathrm{mm})$ & 40 & 50 & 60 & 70 & 80 & 90 & 100 & 110 & 120 & 130 & 140 \\
\hline $\mathrm{k}$ & 0.71 & 0.79 & 0.87 & 0.94 & 1.00 & 1.06 & 1.11 & 1.15 & 1.19 & 1.23 & 1.25 \\
\hline
\end{tabular}

$\mathrm{k}=1.3-30(0.18-t / 1000)^{2}$ if $140 \mathrm{~mm}<\mathrm{t} \leq 180$ $\mathrm{mm}$

The calculated results are tabulated in Table 3 and values of strength, $T$ are to the nearest $0.1 \mathrm{MPa}$. The individual strength of the specimens shall not be less than $1.5 \mathrm{Mpa}$ and the average strength shall not be less than 2.0Mpa according to SANS 1058:2021 for class 1 .

\section{RESULTS AND DISCUSSIONS}

\section{Strength Test}

The strength test gives a direct indication of its capacity to resist loads in structural applications whether they be tensile, compressive, shear or combinations of these. The test is used for three purposes research, quality control and assurance, and determining in place concrete strength.

The strength test was performed on five plastic blocks from the sample; the results obtained were obtained using the formula strength $T$, in megapascal of the block $=0.637 * \mathrm{k} * P / S$ and the results tabulated in Table 3 below. This test is used to determine the effects of various materials or

37 | This work is licensed under a Creative Commons Attribution 4.0 International License. 
mixture proportions on the strength of the samples to establish the resistance of the sample to cracking.

Table 3: Tensile Splitting Test Results

\begin{tabular}{llllllll}
\hline S/No. & $\begin{array}{l}\text { Failure } \\
\text { Load, } \mathbf{P} \\
(\mathbf{N})\end{array}$ & $\begin{array}{l}\text { Thickness, } \\
\mathbf{t}\end{array}$ & $\begin{array}{l}\text { Failure } \\
\text { Length, } \mathbf{l} \\
(\mathbf{m m})\end{array}$ & $\begin{array}{l}\text { Failure } \\
\text { Area, } \mathbf{S}(\mathbf{m m})\end{array}$ & $\begin{array}{l}\text { Plane } \\
\text { (mm) }\end{array}$ & $\begin{array}{l}\text { Correction } \\
\text { Factor, K }\end{array}$ & $\begin{array}{l}\text { Strength, } \\
\text { T } \\
(\mathbf{M p a})\end{array}$ \\
\hline S1 & 38200 & 46 & 196 & 9016 & 0.79 & 2.1 \\
S2 & 29700 & 46 & 184 & 8464 & 0.79 & 1.8 \\
S3 & 32000 & 47 & 189 & 8883 & 0.79 & 1.8 \\
S4 & 42300 & 46 & 190 & 8740 & 0.79 & 2.4 \\
S5 & 43600 & 47 & 189 & 8883 & 0.79 & 2.5 \\
Total & & & & & $\mathbf{1 0 . 6}$ \\
Average & & & & & $\mathbf{2 . 1}$ \\
\hline
\end{tabular}

\begin{tabular}{lll}
\hline Class & Individual & Average \\
\hline 1 & 1.5 & 2 \\
2 & 2 & 2.6
\end{tabular}

The strength of the individual specimens' ranges between 1.8 - 2.5 Megapascals. SANS 1058: 2021 recommends that the individual strength of the tested specimen should be $2 \mathrm{MPa}$. From the above results, the individual strength of the blocks is within the recommended value of not less than $1.5 \mathrm{MPa}$. The average tensile strength is $2.1 \mathrm{MPa}$ which is also above the recommended average of $2.0 \mathrm{Mpa}$.

\section{CONCLUSIONS}

The following conclusions were drawn from the study: -

- The individual strength of the blocks ranged between 1.8 - 2.5 Megapascals; satisfying the specifications.

- The average strength of the five blocks that were tested was 2.1 Megapascals and was within the specifications.

- The plastic paving blocks satisfies all of the specifications laid down by SANS 1058:2021 and therefore can be used for low traffic pavements including walkways and cycle lanes.

\section{RECOMMENDATIONS}

This study makes the following recommendations: -

- Further studies need to be carried out to establish the appropriate mix design for the plastic paving blocks and standards for consistency.

- Further studies are needed to establish the health effects of micro plastics.

\section{REFERENCES}

BS EN 1338: 2003 Concrete Paving Blocks Requirements and Test Methods

Florida Department of Transportation (1999) Florida Pedestrian Planning and Design Handbook

United Nations Environmental Program (2009) Converting Plastic Waster into a Resource; Assessment Guidelines

38 This work is licensed under a Creative Commons Attribution 4.0 International License. 